\title{
M-Government: Measuring the Factors that influence Mobile Government Services Acceptance among Bahraini Youth
}

\author{
Hayat Ali $^{1}$, Reem Sahwan ${ }^{2}$, Zainab Shamsaldeen ${ }^{3}$, Nafeesa Rajulla $^{4}$ \\ College of Information Technology, University of Bahrain \\ Kingdom of Bahrain \\ hali@uob.edu.bh \\ Reem.sahwan@gmail.com \\ Zainab.shamsaldeen@gmail.com \\ nafeesa.Rajulla@gmail.com
}

\begin{abstract}
In recent years, the advancement of Information and Communication Technologies (ICTs) and particularly the rapid changes in mobile technologies have led to the development of new applications. Many governments worldwide have started moving towards Mobile Government (M-Government) as M-government can be a powerful component of the e-government that could facilitate more and better services to the citizens. For a better application of these services, it is important to investigate the factors that influence the intention to use M-government services. Therefore, this study is to investigate the factors that influence the intention to use M-Government services among Bahraini Youth. The theoretical model that was developed by [1] was employed for this purpose. The model is tested through a survey administered to Bahraini Youth. Results suggested Perceived Trust in Technology, Perceived Service Quality, and Perceived Compatibility affect Youth's intention to use M-services. The results also revealed that Ease of Use and Usefulness are antecedents to attitude toward using M-services. This research provides mobile service providers in Kingdom of Bahrain with a practical and communicable checklist of contextual and conditional factors, which are seamlessly integrated, and cover the end user's (Youth) perspectives which should be considered as the cornerstone for any M-Government project.
\end{abstract}

\section{Indexing terms/Keywords}

M-Government, Youth, Acceptance, Mobile Technology Acceptance model (TAM).

\section{Academic Discipline And Sub-Disciplines}

Information Technology

\section{SUBJECT CLASSIFICATION}

Management Information Systems

\section{TYPE (METHOD/APPROACH)}

Survey

\section{Council for Innovative Research}

Peer Review Research Publishing System

Journal: International Journal of Management \& Information Technology

Vol. 9, No. 1

editor@cirworld.com

www.cirworld.com, member.cirworld.com 


\section{INTRODUCTION}

The attractive and efficient features of ' $3 G$ ' and ' $4 G$ ' enabled mobile phones have attracted a lot of people into the world of wireless network specially the Youth sector. Periodical enhancements in the mobile devices have encouraged public and private sectors to use them as a platform to serve the citizens and to offer them vital services such as health care, transportations, governance, public safety, education, etc.

Therefore, the significant of Mobile Technologies are becoming more observed than it was in the past, especially in the public sector as new concept that is becoming widely exchanged that is called 'M-Government'.

M-Government is "the innovative concept, employed by governments to utilize mobile technologies to communicate and offer services to the citizens" [1].The difference between e-Government and M-Government resides in the technique of the transformation of the public services [2]. E-Government offers services through wired network with interactive and intelligent web applications. On the other hand, M-Government comes from the competences of applications supporting mobility for citizens, businesses and internal procedures to support mobility of the typical challenges of E-Government are naturally shared by the M-Government efforts [3].

The M-Government in Kingdom of Bahrain started since the first quarter of 2010 after extensive studies conducted by the e-Government Authority in May 2009. There are three types of M-services which are: SMS, WAP and Mobile applications (one application per service). There are two strategies that the Government adopts; the first strategy is to provide $167 \mathrm{M}$-Services and the second one is to increase it to $200 \mathrm{M}$-Services.

The success of $\mathrm{M}$-Government requires active engagement by both government and its citizens. Providing is one and only aspect of the M-Government equation. However, the more challenging aspect is achieving acceptance and widespread persistent use of M-government by citizens [4,5].

There is a growing body of academic research which has examined acceptance of M-Services among users $[6,7,8$, $9,1]$. Number of theoretical models are available that attempt to explain the relationship between user's attitudes and beliefs in use of technology including the Theory of Reasoned Action (TRA), the Theory of Planned Behavior (TPB), Unified Theory of Acceptance and Use of Technology (UTAUT), and the Technology Acceptance Model (TAM). The objective of this study is: to examine the factors that affect Youth acceptance of using M-Government in Kingdom of Bahrain.

\section{RESEARCH MODEL AND HYPHOTHESES}

This research employed the theoretical framework provided by reference [1] as shown in Fig 1 in which they identified nine major factors as significant antecedents of the intention of citizens to use M-Government. They developed their framework based on several sources including the Theory of Reasoned Action (TRA), the Unified Theory of Acceptance and Use and the Technology (UTAUT), and Acceptance model (TAM) [10], various theories in information systems, social psychology, economics, and culture; and recent published literature on mobile internet or service adoption $[11,12,13]$.

The following hypotheses are postulated:

$\mathrm{H} 1 \mathrm{a}$ : The perceived usefulness of the M-Government service has a significant effect on the attitude towards using mgovernment service

$\mathrm{H} 1 \mathrm{~b}$ : The perceived usefulness of the M-Government service has a significant effect on the behavioral intention to use m-government service

H2a: The perceived ease of use of the M-Government service has a significant effect on the attitude toward using MGovernment service.

$\mathrm{H} 2 \mathrm{~b}$ : The perceived ease of use of the M-Government service has a significant effect on the perceived usefulness of M-Government service.

H3: Attitude toward using M-Government service has a significant effect on behavioral Intention to use M-Government services.

$\mathrm{H} 4$ : Social influence has a significant effect on behavioral intention to use $\mathrm{m}$-government services.

$\mathrm{H} 4 \mathrm{a}$ : Social influence has a significant effect on perceived ease of use of M-Government services.

$\mathrm{H} 4 \mathrm{~b}$ : Social influence has a significant effect on the perceived usefulness of M-Government services.

H5: The perceived service quality of M-Government service has significant effect on behavioral intention to use MGovernment service.

H6: Perceived cost has a significant effect on behavioral intention to use M-Government service.

H7: Perceived risk has a significant effect on behavioral intention to use M-Government service.

H8: Perceived trust in government has a significant effect on behavioral intention to use M-Government service.

H9: Perceived trust in technology has a significant effect on behavioral intention to use M-Government service.

H10: Perceived compatibility has a significant effect on behavioral intention to use M-Government services.

H10a: Perceived compatibility has a significant effect on perceived ease of use of M-Government services.

$\mathrm{H} 10 \mathrm{~b}$ : Perceived compatibility has a significant effect on the perceived usefulness of M-Government service. 


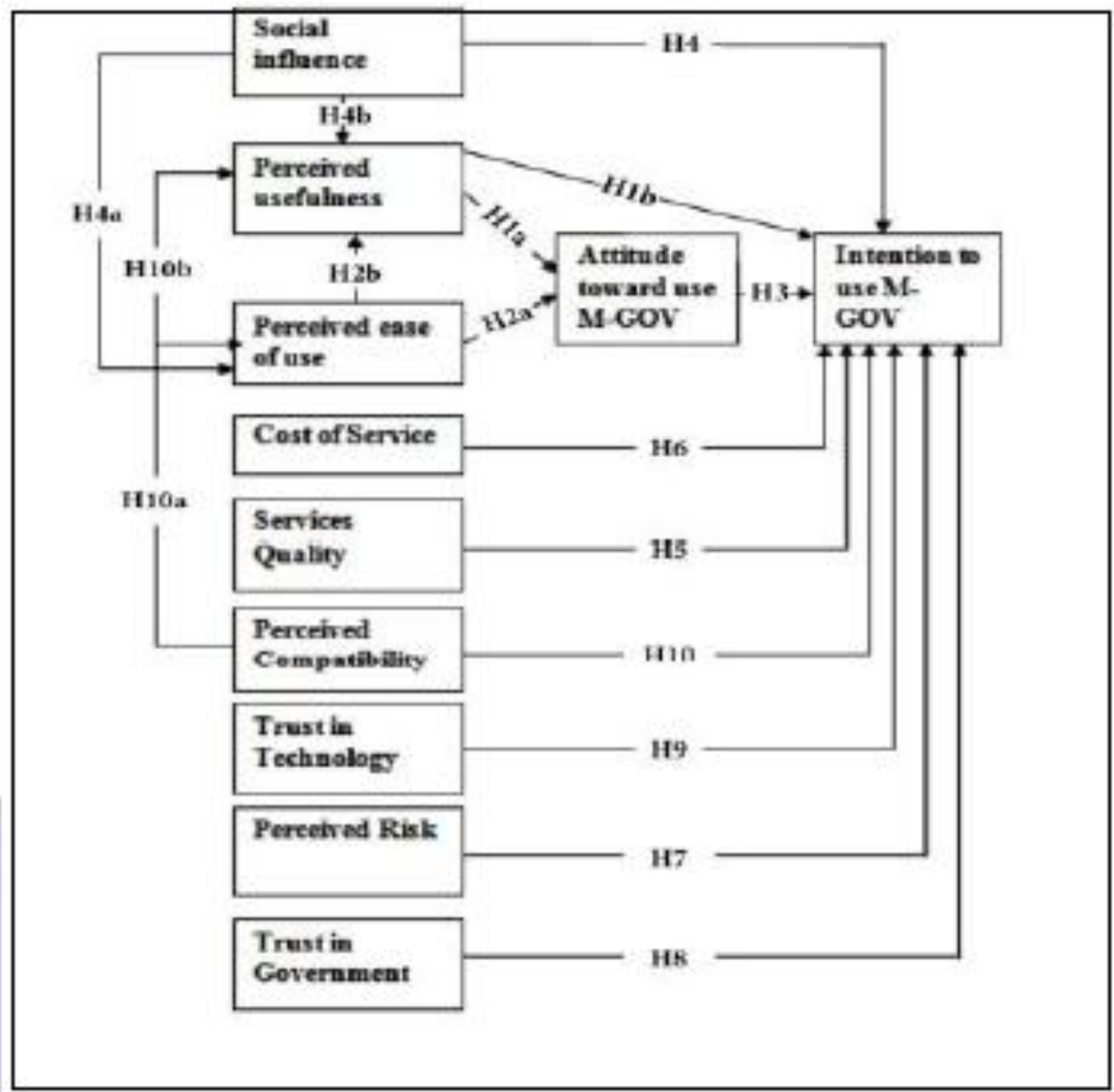

Fig 1: Factors influence M-Government services Model [1]

\section{DATA COLLECTION}

A total of 136 citizens responded to the questionnaire survey. The data from 136 respondents were analyzed using SPSS. The demographic distribution as shown in Table I that $72.1 \%$ of the respondents were male and the remaining $27.9 \%$ were female. With respect to age, most of the respondents (52.2\%) were between 22 to 24 years. This age group has potential to become users of $\mathrm{m}$-government because of their familiarity with the latest mobile technologies $[14,15]$.

Table 1. Demographic Distribution

\begin{tabular}{|c|c|c|}
\hline \multirow{2}{*}{ Attribute } & \multicolumn{2}{|c|}{ Demographic Distribution } \\
\hline & Frequency & Percentage \\
\hline \multicolumn{3}{|l|}{ Gender } \\
\hline Male & 98 & $72.1 \%$ \\
\hline Female & 38 & $27.9 \%$ \\
\hline \multicolumn{3}{|l|}{ Age } \\
\hline $16-18$ & 7 & $5.1 \%$ \\
\hline $19-21$ & 38 & $27.9 \%$ \\
\hline $22-24$ & 71 & $52.2 \%$ \\
\hline $25-27$ & 10 & $7.4 \%$ \\
\hline $28-30$ & 10 & $7.4 \%$ \\
\hline
\end{tabular}




\section{QUESTIONNIARE DEVELOPMENT}

The items were formulated as Likert-type statements anchored by a five -point scale, ranging from 1 ("strongly disagree") to 5 ("strongly agree"). Generally the researchers are to obtain the level of validity by asking questions and look for the answers, and often look for the answers in the research of others. The values of Component Extracted are all above 0.5 which are at acceptable level [16]. Table 2 presents the results of alpha coefficients for each factor with reliability analysis. Conbach's alpha values of each construct are from 0.797 to 0.951 . Indicating a level above 0.70 ; the threshold recommended by reference [17].

Table 2. Cronbach's Alpha for Each Factor

\begin{tabular}{|c|c|}
\hline Factors & Cronbach's Alpha \\
\hline Perceived Usefulness(PU) & .880 \\
\hline Attitude Toward Use M-Gov services (ATU) & .797 \\
\hline Social Influence (SI) & .951 \\
\hline Service Quality (SQ) & .822 \\
\hline Cost of Service (CS) & .800 \\
\hline Perceived Risk (PR) & .881 \\
\hline Perceived Trust in Technology (PTT) & .883 \\
\hline Perceived Trust in Government (PTG) & .837 \\
\hline Perceived Ease Of Use (PEOU) & .910 \\
\hline Behavioral Intention (BI) & .878 \\
\hline
\end{tabular}

\section{HYPOTHESES TESTING}

As the research model involves more than one dependent variable the multiple regression analysis is used to test the hypotheses. In addition to this, the linear regression cannot test all the relationships in a single statistical test; therefore, it is necessary to use three separate regressions to test the model fully [18].

The first regression analysis was run for $\mathrm{H} 1 \mathrm{~b}, \mathrm{H} 3, \mathrm{H} 4, \mathrm{H} 5, \mathrm{H} 6, \mathrm{H} 7, \mathrm{H}$ 9, and $\mathrm{H} 10, \mathrm{BI}$ is the dependent variable while $\mathrm{SI}$, SQ, PU, ATT, CS, PC, PTT, PTG and PR are the independent variables

The coefficient of determination $\left(\mathrm{R}^{2}\right)$ measures the proportion of the variance of the dependent variable about its mean that is explained by the independent or predictor variables [19]. (The higher the value of $R^{2}$, the greater the explanatory power of the regression model.

The regression model $\mathrm{R}^{2}$ value for the dependent variable behavioral intention $(\mathrm{BI})$ is 0.669 , meaning that $66.9 \%$ of the variance in behavioral intention is explained by the regression model. This value is considered high and thus the power of the regression model is good.

As the research model involves more than one dependent variable the multiple regression analysis is used to test the hypotheses. In addition to this, the linear regression cannot test all the relationships in a single statistical test; therefore, it is necessary to use three separate regressions to test the model fully [18].

The first regression analysis was run for $\mathrm{H} 1 \mathrm{~b}, \mathrm{H} 3, \mathrm{H} 4, \mathrm{H} 5, \mathrm{H} 6, \mathrm{H} 7, \mathrm{H} 9$, and $\mathrm{H} 10, \mathrm{BI}$ is the dependent variable while SI, SQ, PU, ATT, CS, PC, PTT, PTG and PR are the independent variables

The coefficient of determination $\left(R^{2}\right)$ measures the proportion of the variance of the dependent variable about its mean that is explained by the independent or predictor variables [19] The higher the value of $R^{2}$, the greater the explanatory power of the regression model. 
The regression model $\mathrm{R}^{2}$ value for the dependent variable behavioral intention $(\mathrm{BI})$ is 0.669 , meaning that $66.9 \%$ of the variance in behavioral intention is explained by the regression model. This value is considered high and thus the power of the regression model is good.

Table 3. Behavioral Intention Regression Analysis

\begin{tabular}{|c|c|c|c|}
\hline Model & Standardized Coefficients & T & .126 \\
\hline SI & Beta & 1.540 & .354 \\
\hline CS & .108 & .929 & .021 \\
\hline SQ & .059 & 2.333 & .000 \\
\hline PC & .190 & 3.801 & .633 \\
\hline ATT & .328 & -.479 & .368 \\
\hline PR & -.049 & -.659 & .015 \\
\hline PTG & -.044 & .903 & .287 \\
\hline PTT & .076 & 2.454 & 1.069 \\
\hline PU & .106 & & \\
\hline
\end{tabular}

Table 3 presents these first regression variables. The results show determinants of $\mathrm{BI}-\mathrm{SI}, \mathrm{PU}, \mathrm{ATT}, \mathrm{CS}, \mathrm{PTG}$ and PR were found to be insignificant. However, SQ, PC, and PTT were found to be significant.

The regression model supports the following hypothesis:

H10: Perceived Compatibility has a significant effect on behavioral intention to use M-Government services $(\beta=0.000$, $\mathrm{p}<0.05)$.

H9: Perceived Trust in Technology has a significant effect on behavioral intention to use M-Government service $(\beta=0.015, p<0.05)$.

H5: The Service Quality of M-Government service has significant effect on behavioral intention to use M-Government service. $(\beta=0.021, p<0.05)$.

However, it does not support the following hypotheses:

$\mathrm{H} 1 \mathrm{~b}$ : Perceived usefulness of the M-Government service has no significant effect on the behavioral intention to use MGovernment service.

H3: Attitude toward using M-Government service has no significant effect on behavioral Intention to use MGovernment services.

$\mathrm{H} 4$ : Social influence has no significant effect on behavioral intention to use M-Government services

H6: Perceived Cost has a significant effect on behavioral intention to use M-Government service.

H7: Perceived Risk has a significant effect on behavioral intention to use M-Government service.

H8: Perceived Trust in government has a significant effect on behavioral intention to use M-Government service.

The second regression analysis was run for $\mathrm{H} 2 \mathrm{~b}, \mathrm{H} 4 \mathrm{~b}$ and $\mathrm{H} 10 \mathrm{~b}$. $\mathrm{PU}$ is the dependent variable while PEOU, SI and $\mathrm{PC}$ are the independent variables.

Table 4 presents these second regression variables. The results show that perceived ease of use (PEOU) and social influence (SI) have a significant effect in predicting of PU.

The regression model $R^{2}$ value for the dependent variable usefulness (PU) is 0.653 , meaning that $65.3 \%$ of the variance in usefulness is explained by the regression model.

Table 4. Perceived Usefulness regression Model

\begin{tabular}{|c|c|c|c|}
\hline \multirow{2}{*}{ Model } & Standardized Coefficients & t & Sig. \\
\cline { 2 - 3 } & Beta & 4.263 & .000 \\
\hline SI & .272 & 2.384 & .019 \\
\hline PC & .190 & 6.116 & .000 \\
\hline
\end{tabular}


The regression model $R^{2}$ value for the dependent variable usefulness (PU) is 0.653 , meaning that $65.3 \%$ of the variance in usefulness is explained by the regression model.

The second regression model supports the following hypotheses:

$\mathrm{H} 2 \mathrm{~b}$ : Perceived ease of use of the M-Government service has a significant effect on perceived usefulness of the MGovernment service $(\beta=0.469, p<0.05)$.

H4b: Social influence has a significant effect on the perceived usefulness of $M$-Government services $(\beta=0.272$, $\mathrm{p}<0.05)$.

H10b: Perceived compatibility has significant effect on perceived usefulness of the M-Government service $(\beta=0.190$, $\mathrm{p}<0.05)$.

The third regression analysis was run for $\mathrm{H} 4 \mathrm{a}$ and $\mathrm{H} 10 \mathrm{a}$. Perceived Ease of Use (PEOU) is the dependent variable while SI and PC are the independent variables. Table 5 presents the third regression model variable. Results show that the two determinants of PEOU were found to be significant in predicating PEOU M-Government services.

Table 5. Perceived Ease of Use Regression Model

\begin{tabular}{|c|c|c|c|}
\hline \multirow{2}{*}{ Model } & Standardized Coefficients & & \multirow{2}{*}{ Sig. } \\
\cline { 2 - 3 } & Beta & $\mathbf{t}$ & .029 \\
\hline SI & .157 & 2.212 & .000 \\
\hline
\end{tabular}

The regression model $\mathrm{R}^{2}$ value for the dependent variable PEOU is 0.552 , meaning that $55.2 \%$ of the variance in PEOU is explained by the regression model.

The third regression model supports all hypotheses:

$\mathrm{H10a}$ : Perceived compatibility has a significant effect on perceived ease of use M-Government services $(\beta=0.642$, $\mathrm{p}<0.05)$.

$\mathrm{H} 4 \mathrm{a}$ : Social influence has significant effect on perceived ease of use of $\mathrm{M}$-Government services $(\beta=0.157, p<0.05)$.

The fourth regression analysis was run for $\mathrm{H} 1 \mathrm{a}$ and $\mathrm{H} 2 \mathrm{a}$. Attitude toward use Technology (ATT) is the dependant variable while PEOU and PU are the independent variables. Table 6 presents the fourth regression model variable. Results show that the two determinants of ATT were found to be significant in predicating ATT toward use MGovernment services.

Table 6. Attitude Regression Model

\begin{tabular}{|c|c|c|c|}
\hline \multirow{2}{*}{ Model } & Standardized Coefficients & \multirow{2}{*}{ T } & Sig. \\
\cline { 2 - 3 } & Beta & T & .002 \\
\hline PEOU & .236 & 3.130 & .000 \\
\hline PU & .625 & 8.284 & \\
\hline
\end{tabular}

The regression model $R^{2}$ value for the dependent variable ATT is 0.669 , meaning that $66.9 \%$ of the variance in ATT is explained by the regression model.

The fourth regression model supports the following hypotheses:

$\mathrm{H} 1 \mathrm{a}$ : Perceived usefulness of the M-Government service has a significant effect on the attitude toward using $M$ Government service $(\beta=0.625 p<0.05)$.

H2a: Perceived ease of use of the M-Government service has a significant effect on the attitude toward using $M$ Government service $(\beta=0.236, p<0.05)$

\section{RESULTS AND DISCUSSION}

This research main objective was to investigate the factors that influence the acceptance of M-services by Youth in Kingdom of Bahrain Building on the existing Technology Acceptance using the model of acceptance proposed by reference [1]. Overall, good support was found for the presented hypothesis using a sample of 136 participants.

The factors that may affect Youth intention to use M-services are: Perceived Usefulness, Perceived Ease of Use, Attitude toward use, Perceived compatibility, Social influence, Perceived Risk, Perceived Cost, Perceived Trust in Technology, Perceived Trust in Government Service Quality, and Behavioral intention.

The factors that support the Behavioral Intention in our result were Perceived Compatibility, Service Quality and Perceived Trust in Technology; which had a positive effect on user's intention to accept M-Government service. As reference [20] suggested an idea that more compatible was more convinced to the potential adopter; therefore, its adoption could be accelerated. New M-Government services should be seamlessly integrated into citizen transaction without requiring extraneous steps, equipment and training. Therefore, the M-Government services should be designed in a way to enforce these aspects by citizens. The M-Government services experience should also be helpful to enhance Youth lifestyle. 
However, Social Influence, Perceived Risk, Perceived Trust in Government, Perceived Cost and Attitude toward were rejected by the tested hypotheses are not significance toward Youth Behavioral Intension.

The influence of Usefulness was determined by Perceived Ease of Use, Social Influence and Perceived Computability; which had a positively effects on user's perceived usefulness of accepting M-Government services. Relying on the finding, friends and families had a great influence toward adopting the M-Government services. Also, the Youth believe that if the services were easy, easy to get the services and understandable; it will enhance them to believe that the services are useful. These results should give an insight for designing the M-Services in a highly easy manner with the focus on the social context of the Youth who influence their acceptance toward using M-services.

The third regression tested the relationship of Perceived Ease of Use with Perceived Computability and Social influence. The results revealed that both the Compatibility and Social influence had significant effects on Youth to consider that if the service was compatible; it will be easy to use. Therefore, the designs of the M-Services have to be understandable and well compatible with their needs. Also, the result illustrated that the Social Influence toward using the M-Government services will amplify the ease to use them because the more people around the person using such of technology, it will give them the encouragement to try it and adopt it.

At last, Attitude toward Using the M-Government was supported by two factors. Perceived Usefulness (PU) and Perceived Ease of Use (PEOU) were the original constructs in TAM, and they have been found to affect the Acceptance of Technology-enabled products and services by many prior studies. Therefore, it is not surprising to find that they also affect Youth's acceptance of M-Government services. According to reference [21] and [10], it was suggested that the inclusion of attitude is not meaningful. But our results suggested otherwise Therefore, the Government should make sure that offered M-Services should be useful to the Youth and target their needs as well as easy to use as a wayto enforce their attitude toward using M-Service.

\section{CONLUSION AND FURTHER WORKS}

This research was investigating the factors influence Youth's acceptance of using M-Government Services in Kingdom of Bahrain. Toward the achievement of these objectives, quantitative approach through which a questionnaire as used as a research instrument.

The findings suggested some factors that have significant influence on accepting M-services by Youth which are Perceived Trust in Technology, perceived service quality, and Perceived Compatibility. The result also revealed that attitude toward using M-services is affected by ease of use and usefulness.

The strength of this research resides on its scope as it concerned with a new area of E-Government application that need to be measured specially for Youth sector in the context of Kingdom of Bahrain it just started their applications since 2010. However, the weakness resides on the difficulty of generalizing the results because of small sample size that was included in this research.

The findings from this study have a number of important implications to both researchers and practitioners. Since this is the first known study that investigates Youth acceptance of M-Government services in the Kingdom. It will provide the theoretical foundation for researchers to develop future studies. For practitioners, understanding the key constructs in the proposed research framework is crucial in the design and development of M-Government services with high citizen acceptance. Using the research results, the following recommendations can be suggested:

-New M-Government services should be seamlessly integrated into citizen transaction without requiring extraneous steps, equipment and training. Therefore, the M-Government services should be designed in a way to enforce these aspects by citizens

-The M-Services should be designed in a highly easy manner with the focus on the social context of the Youth that influences their acceptance toward using M-services.

-The design of the M-Services has to be understandable and well compatible with Youth experience, expectation and objectives.

-The Government should make sure that the offered M-Services are useful to the Youth and target their needs as well as easy to use as a way to enforce their attitude toward using M-Services.

As a future work, this research has to be expanded to increase the sample size with measuring other dimensions of M-services such as its impact on Youth quality of life and its impact on other stakeholders, including businesses, Government agencies, Non-profit organizations and Non-Government organizations.

\section{REFERENCES}

[1] A, Althunibat, N. Mat zain and N, Sahari, "Modelling the factors that influence mobile". African Journal of Business Management vol. 5(34), 2011, pp. 13030-13043.

[2] I, Kushchu and H Kuscu, "From E-Government to M-Government: Facing the Inevitable". Proceedings of European Conference on E-Government (ECEG), 2003. Dublin:Trinity College.

[3] A, Al-Hadidi and Y, Rezgui, "Critical Success Factors for the Adoption and Diffusion of m-Government Services". Proceedings of 9th European Conference on e-Government, 2009, London, UK.

[4] J, Carroll, "Risky Business: Will Citizens Accept M-government in the Long Term?" EURO mGOV, 2005, Brighton, UK, pp. 77-87. 
[5] J, Carroll, "What's in It for Me? Taking M.Government to the People", University of Melbourne, Australia, 19th Bled eConference, 2006.

[6] J Van Biljon and P, Kotzé, "Modelling the Factors That Influence Mobile Phone Adoption", ACM, 2007, pp. 152-161.

[7] S, Gao J, Krogstie and PA, Gransaether "Mobile Services Acceptance Model". CHIT '08 Proceedings of the 2008 International Conference on Convergence and Hybrid Information Technology, 28-29 August, 2008 pp. 446-453

[8] M, Mohamedpour, ZM, Faal and M, Fasanghari "A Proposed Framework for Effective Mobile Services Acceptance Factors", IEEE, 2009 pp. 250-255.

[9] SD, Sudha, DK, Singh, MK, Singh and SK, Singh, "The Forecasting of $3 g$ Market in India Based on Revised Technology Acceptance Model". Int. J. Next-Generation. Networks,vol. 2( 2), 2010,pp.61-68.

[10] FD , Davis, "Perceived Usefulness, Perceived Ease of Use, and User Acceptance of Information Technology". MIS Q.,1989, pp. 319-340.

[11] H, Dai and PC, Palvi, "Mobile Commerce Adoption in China and the United States: A Cross-Cultural Study". ACM SIGMIS Database, vol. 40, 2009, pp. 43-61.

[12] J, Lu, JE, Yao and CS, Yu, "Personal Innovativeness, Social Influencesand Adoption of Wireless Internet Services Via Mobile Technology". J.Strateg. Inform. Syst., vol. 14, 2005 pp.245-268.

[13] H, Rosenbaum and B, Kleber, "A Socio-Technical Analysis of M-Commerce in Japan: Research in Process", in Proceedings of the Tenth Americas Conference on Information Systems, New York, New York, August, 2004.

[14] A, Al-Thunibat, N, Zin, N, Sahari, "Mobile goverbnemnt user requirements model", Journal of e-Governance, vol.34(2),2011 pp. 104-111.

[15] K. Moore and J. Rutter, "Understanding Consumers' Understanding of Mobile Entertainment.," in Proceedings of Mobile Entertainment:User-centered Perspectives, Manchester, England, 2004

[16] N Van Saane, JK, Sluiter,JHVerbeek and MH, Frings-Dresen, "Reliability and Validity of Instruments Measuring job Satisfaction-a Systematic Review". Occupational Medicine,vol. 53 (3), 2003, pp. 191-200.

[17] J, Nunnally J,I, Bernstein and J, Berge J, "Psychometric Theory". New York.:McGraw-Hill, 1967.

[18] D, Gefen, D Straub and MC, Boudreau, "Structural Equation Modeling and Regression: Guidelines for Research Practice". ACM, vol. 4(7), 2000, pp. 1-79.

[19] J.F. Jr., Hair, R.E, Anderson, R.L, Tatham and W.C Black, " Multivariate Data Analysis". 5th Ed. NJ. USA:PrenticeHall.Upper Saddle River, 1998.

[20] M, Abbad, D, Morris and C, de Nahlik, "Looking under the Bonnet: Factors Affecting Student Adoption of ELearning Systems in Jordan". International Review of Research in Open and Distance Learning 10, 2009, p 10.

[21] D.A, Adams., R.R., Nelson and P.A. Todd, "Perceived usefulness, ease of use, and usage of information technology: A replication", MIS Quarterly, vol. 16, 1992, pp.227-247.

\section{Authors' biographies}

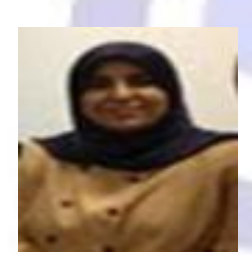

Hayat Ali is an Assistant Professor in Information Systems Department at College of IT. She has 10 years of research experience in the field of e-government, e-democracy and e-participation. She earned her Ph.D from University of Manchester since 2010. She participated in many conferences and expert workshops in e-government inside and outside Kingdom of Bahrain. She is a member in Association for Information Systems (AIS); Association for Computer Machinery Digital Government Society of North America (DGSNA) and IEEE.

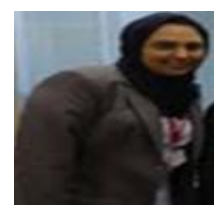

Zainab Khalil earned her B.Sc. in Information Systems from University of Bahrain.

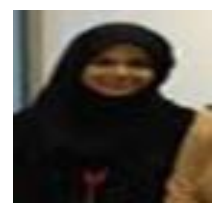

NafeesaRajulla earned her B.Sc. in Information Systems from University of Bahrain.

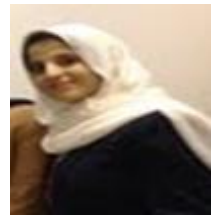

ReemSahwan earned her B.Sc. in Information Systems from University of Bahrain. 